
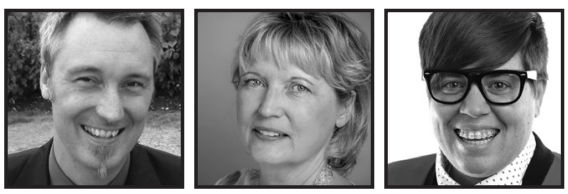

\title{
Professional Development That Positions Teachers as Inquirers and Possibilizers
}

\author{
Leyton Schnellert, Donna Kozak, and Shelley Moore, \\ University of British Columbia
}

\begin{abstract}
What might braiding social justice orientations to teaching, learning, and educational change with collaborative inquiry-based professional development afford teachers, their students, and our communities? This article unpacks two professional development initiatives to articulate how inquiry co-constructed by and with teachers can take up diversity as generative. The Aboriginal Early Literacy and Curriculum for All projects involved iterative and critical examinations of practice and opportunities for educators to collaboratively consider and create practices that address contextual and social factors. Educators worked together to situate emerging knowledge and beliefs while also challenging the sources and consequences of assumptions.
\end{abstract}

n this piece we recast professional development as a practice of inquiry co-constructed by and with teachers that includes an ongoing, iterative, and critical examination of practice and the opportunity to collaboratively consider and address contextual, social, and discursive factors (Ball, 2009; Moll, 2014). Through collaborative inquiry, educators can work together to situate emerging knowledge and beliefs while also challenging the sources and consequences of assumptions. Here we offer two examples of collaborative inquiry communities to illustrate the co-creation of interactional spaces where over time multi-voiced contributions of insight, knowledge, pedagogy, and generativity refreshed educators' theories of action. Agency within such an endeavor not only includes the purposeful transformation of classroom practice, but also an opportunity to change discourse itself. 


\section{Theoretical Framework}

As with both theory and practice, much of the basis for collaborative inquiry-based learning draws on the work of Dewey (1938a, 1938b). Dewey felt that rich learning opportunities could be achieved from the integration of an individual's interests with those of society. Dewey theorized how the social nature of inquiry can enrich ways that we understand knowledge construction by suggesting that knowledge is shaped through the active engagement of diverse perspectives within a community (Bishop et al., 2004; Cranton, 1996).

Werstch (2010) writes of cultural tools, framed by Vygotsky's (1978) conception of socio-cultural tools and thought methodologies, as introducing historical and political dimensions that shape cognition and ultimately mediate discursive practices. Vygotsky (1987) believed language serves communication by supporting humans to coordinate their actions with others through the creation of meaning mediated through social relationships; Moll (2014) extends this work to include professional learning partnerships or groups. Embedded in sociocultural activities are invisible mediations deployed through language use which help humans internalize the social world they experience as well as shape particular dispositions, habits of mind, attention, interests, and motivation. Learning is always a cultural and relational process as we learn through the mediation of others whether it be through direct social interactions, cultural artifacts, or the appropriation of language in both formal or informal settings (Moll, 2014; Wells, 2007). Collaborative inquiry as an approach to professional development holds great promise in terms of attending to teachers', schools', and communities' social worlds and their intersections.

In our work we take up community-based approaches to counter simplistic notions of inquiry that fail to capture many of the factors at play. Community-based inquiry emerges as a broad paradigm-crossing conceptual frame for communities of researchers and professionals. Community, first and foremost, acknowledges the importance of context, extending beyond geography to include social perspectives. In a community approach to inquiry learning, a community forms or members of a community gather to address their aspirations, capabilities, and challenges (Schnellert \& Butler, 2014).

Inquiry communities of educators can work together within interactional spaces to develop contextually based discourse practices that enable the co-creation of thought and the development of a common theoretical vocabulary. Greeno (2012) defines this new discourse as a "functional concept" or a cognitive entity that has meaning in a 
particular kind of activity which contributes to the ways participants organize their understandings of their practices. These functional concepts are represented and enacted through new theoretical shared vocabulary which are internalized leading to action challenges and transformation of practices (Bazerman, 2012). Moll (2014) suggests that teachers, more than anyone else, must engage in action challenges as a daily component of their practice:

Creating spaces for discussion is a central aspect of teachers' intellectual development as professionals, which includes their acquisition of functional concepts. .... [T]eachers change themselves in the process of helping to mobilize funds of knowledge for teaching and learning and working with others to help change classrooms for the better. (151-154)

In this way, inquiry communities work as a mediating structure allowing teachers to develop intersubjective ways of knowing and transacting while adding to their funds of pedagogy.

A teaching community can consider qualities and factors that are unique to the group and issues within their local setting (Dillon, O'Brien, \& Heilman, 2000; Schnellert \& Butler, 2014). By acknowledging the various aspects and challenges the context brings to learning, a situated group inquiry process begins. This work is rooted in a social framework of inquiry which views knowledge as constructed through both experience and dialogue. The group of inquirers is motivated by a position or an issue and is often ethically and philosophically driven to find an answer (Schnellert \& Butler, 2014). Inquiry community approaches to professional development are widely seen as having the potential for significant impact in classrooms and super-structures such as policy:

teachers who are members of professional networks or learning communities may find themselves more apt to venture into the unknown, to engage in long-term inquiry, and/or to share what they are learning with others than those who are unsupported by their colleagues. (Van Horn, 2006, p. 61)

While the premise of this approach is that teachers generate local knowledge of and for teaching, determining the sources and consequences of assumptions must also play a role. Efforts to examine how to increase student success and make schools and classrooms more democratic are more likely to be sustained when teachers with personalized questions and diverse perspectives participate together in a community of inquiry. 
If meaning is inseparable from and contingent upon context (i.e., a situated perspective), the design of a community's inquiry might change over time to be responsive to the unique factors of the research/learning situation, especially as members discover and challenge previously held assumptions (Schnellert, Richardson, \& Cherkowski, 2014). In the case of inquiry communities, the purposeful application of social learning theory gathers momentum when teachers collaboratively study the influences behind their questions and contexts and identify related or absent discourses.

\section{Professional Inquiry Communities as Mediating Structures for Socially Just Pedagogies}

In this article we offer two examples of inquiry communities where educators examined their practice, drew on theoretical concepts that are inclusion- and social justice-oriented, and generated new knowledge through seeking and celebrating the funds of knowledge of diverse learners, community members, themselves, and one another as pedagogical resources. These narratives of professional development within inquiry communities occurred in two different school districts, yet there were common qualities that offered rich analysis opportunties. At their core, each initiative allowed participants to grow in safe spaces where risk taking was encouraged in an effort to foster new discursive practices.

Each of these inquiry communities occurred within school districts as part of their ongoing professional learning programs and plans. One contribution of this research is that researchers (the authors here) participated as facilitators and resources to the inquiry communities (Butler \& Schnellert, 2012). Participants did not have to take part in the research, rather after the initiatives ended, they were invited to share their learning. Thus, we attended to more naturalistic, organic accounts rather than examining projects that were bounded by university researcher-dominated designs. We participated as inquiry partners facilitating these situated, ongoing, co-constructed communities. Ethics approval was obtained at our institutions and members of the inquiry communities were invited to participate in the research by reflecting on inquiry cycles that took place over the previous school year. In this way they participated in the research knowing what was to be discussed, what had transpired, and with full ownership and agency regarding their learning and experience. Ball (2009) suggests that through lived collaborative experiences, thinking is mediated in powerful ways. We attended to participants' narratives of experience within their respective inquiry 
communities - considering the structure of the projects, what educators did, and what they learned.

Multiple forms of data created as part of the inquiry communities were analyzed retrospectively. Data included interviews, reflective writing, artifacts created within the project such as classroom resources, and email communications.

\section{Design of Learning Communities}

Several qualities are common across these and other inquiry communities we have worked with (e.g., Butler \& Schnellert, 2012; Butler, Schnellert \& MacNeil, 2015; Schnellert $\&$ Butler, 2014). Each of the inquiry communities involved teacher collaboration and iterative inquiry, were situated in a specific geographic and cultural context, and participants were acknowledged for and invited to share their knowledge and expertise. The two projects we discuss here include a school district initiative to support classroom teachers and First Nations advocates to collaborate to integrate Indigenous knowledges into curriculum and teams of classroom teachers and learning assistance teachers collaborating to disrupt deficit orientations to students with developmental disabilities as they worked together to design curriculum using principles from universal design for learning. In each case the inquiry group was a mediating structure for transforming practice and understandings. Both groups met multiple times during the school year. Each of these learning communities positioned teachers as inquirers and possibilizers. By possibilizers we mean that teachers were welcomed to inquiry communities as active versus passive agents. Participating educators had the discretion to choose and create their own path and practices (Fekadu, 2014).

\section{The Aboriginal Early Literacy Project}

A rich Aboriginal student support program has developed in a southern $B C$ school district over the past few years affording students of Aboriginal descent with support in the form of Aboriginal Student Advocates, who from the perspective of a shared cultural heritage, serve as a network among students, their families, and other school personnel. District leaders in Aboriginal Education and Early Literacy came together with questions around how to facilitate opportunities for the Aboriginal Advocates and the teachers of the students they serve to work together in ways that could perhaps transform their roles from sharing a common space to working together within a community of meaningful and collaborative practice. The dual-lens approach of 
Aboriginal Education and Early Literacy led to an invitation to grade one teachers and their school-based advocates to join together in an inquiry-based learning community. Twenty-two grade one teachers and 20 Aboriginal advocates representing 18 schools came together on three occasions from February to June to explore the inquiry question: "How can we enhance the learning for all students in grade 1 classrooms through integrating Indigenous knowledge and early literacy practices?"

The new British Columbia draft curriculum (BC Ministry of Education, 2014) and the First Peoples Principles of Learning (FNESC, 2014) were resources for collaborative inquiry while culturally responsive pedagogy served as the theoretical framework (Gay, 2000, 2002; Ladson-Billings, 1995).

Since part of the strategy in bringing teachers together with the Aboriginal advocates was to realize a more meaningful and effective collaborative partnership around student learning in classrooms, a literacy-focused photo-book project became the vehicle through which this collaboration was realized. Based on the design of an Ontario study (Cleovoulou et al., 2013), the photo-book project became the catalyst to not only bring participants' respective pedagogical and Indigenous knowledges together, but also to embed developmentally appropriate and inclusive early writing practices in classrooms. The use of students' own stories from their homes was a strategy in keeping with the principles of culturally responsive pedagogy (Gay, 2002; Roswell, 2006).

The first collaborative session was held in a First Nations School Association school where the teachers and advocates experienced traditional teachings from an Elder, songs and drumming from the Band school's students, traditional food, as well as an opportunity to get to know each other in a context away from their classrooms and schools. The First Peoples Principles of Learning (FNESC, 2014) was a framework through which participants' co-learning was nurtured. For example, learning involves patience and time became an enduring principle that guided: the building of relationships and community; invitations to (re)examine potentialities for Aboriginal advocates to have a more meaningful place in classrooms; and pedagogical knowledge development related to children's literacy.

The second group inquiry session was held two months later; collaborative partners were able to share their experiences and the progress of their photo-book project with each other. The opportunity to engage in dialogue and integrate their respective experiences led to deeper culturally responsive pedagogical understandings as well as motivation to continue and expand their professional learning. The Medicine Wheel 
(Bell, 2014) and the First Peoples Principles of Learning were used as lenses through which the photo-book project was revisited. The iterative nature of returning to the key concepts led to deeper understandings and richer dialogue. One of the most powerful collective learning experiences was the Aboriginal Talking Circles where all perspectives were shared equally among the community of 60 educators (First Nations Pedagogy Online, 2009). The talking circle added to the co-created funds of pedagogy for the teachers and advocates to use with their students.

The third and final session was one of celebration where teachers and advocates were invited to bring samples of their students' photo-books to share gallery-style. The participants decided this meeting should occur at the original Indigenous education site where a collection of students shared their photo-books in authors' circles. Teachers and advocates jointly analyzed their students' writing using a developmental continuum which fostered a rich conversation around how students develop early literacy skills. The final task was to consider how the student photo-books and the entire inquiry experience fueled and enriched curriculum while contributing to teachers' funds of pedagogy which according to Zipin (2009) are the ways of knowing and transacting knowledge related to life experiences of learners. This is echoed in this written reflection from a grade one teacher:

I definitely gained newfound respect for the students and their families! Hearing all of the incredible things they do, know, and discuss as a family was very eye-opening as a new teacher in a lower SES school. It caused me to hold my students in a higher regard and notice how open-ended the curriculum can be if you let the students lead the way! Because I was learning so much from my students, I was eager to share their stories/what I was doing in the classroom with my advocate, colleagues, and parents. With the help of my advocate, I was incorporating a lot more FN vocabulary: "medicine wheel", "regalia," "Okanagan language..." and FN practices: talking circle/ seeking FN speakers to be guests in our classroom. Our advocate would add to our conversations, sharing her knowledge and expertise, and in turn, I would share my literacy knowledge/vocabulary so she could effectively help the students.

Generativity is a term used by Ball (2009) to describe teachers' abilities to add to their understandings by integrating new personal and professional knowledge with existing knowledge while also reconsidering existing knowledge in light of the new understandings they are constructing. The teacher's knowledge becomes generative as theories translate into practices with students. The teachers continue learning through and with students within the context of their classrooms where the intersection of theory and practice is realized and their students act as pedagogical resources in the 
teaching-learning process (Ball, 2009). Transformational shifts in thinking and acting were shared in participants' reflections:

I feel like this project has provided support to our Aboriginal and non-Aboriginal students in many ways. First, it has allowed students to better understand and embrace their culture. Students seemed more open and receptive to share stories about their families/traditions and began to show pride in their culture. Many students actively volunteered to bring in culturally significant artifacts to share about their culture. It was really neat to learn from them! Second, it has assisted students to better understand cultural diversity; our non-Aboriginal students can have a positive appreciation of the Aboriginal culture and vice versa. (grade one teacher, written reflection)

The teachers and advocates in the collaborative inquiry community experienced generative change on at least two levels: relational and pedagogical. The interactional space that was created for the teachers and advocates facilitated discourse that enabled them to think, plan, design, and talk together about what they were learning and how that could be realized in their classrooms. The project gave them a common theoretical vocabulary and functional concepts (Greeno, 2012) that mediated the way the partners organized their understandings of culturally responsive literacy practices and ways they could collaborate. Over five months, including three learning community sessions, participants' collaborative learning was mediated through co-creation of thought, experiences, and ongoing iterative dialogue between both school-based partners and colleagues from other sites:

Our advocate would add to our conversations, sharing her knowledge and expertise, and in turn, I would share my literacy knowledge/vocabulary so she could effectively help the students (grade one teacher, written reflection).

A very overwhelming feeling of relationship developed between the advocates and teachers, which of course, enhanced the learning for students. In particular the skills, knowledge and interests the advocates bring to the classrooms interrupted many teachers' beliefs about the value of the advocates in the schools. (district support teacher, email communication)

Bakhtin (1981) writes of an individual's ideological becoming through engagement with new perspectives, ideas, and voices. In this project, participants engaged with the discourses of others (including theory and Indigenous ways of knowing) which influenced the way they thought, the development of their own internal persuasive 
discourse, and how they contributed to dialogue with others (Wells, 2007). These transformational shifts ultimately led to changes in educators' thoughts, beliefs, ideologies, and even ways of theorizing. A process of ideological becoming (Ball, 2009; Hedges, 2015; Wells, 2007) contributed to an increased sense of agency, voice, and efficacy for many teachers. For example, collaboration mediated an opening for knowledge creation and space for Indigenous knowledge holders in classrooms:

The Aboriginal Advocate I have been working with gives my students the gift of her knowledge about Aboriginal culture in a way that I am not able to on my own... We sit in a circle and use a talking stick to share about our feelings and sometimes our questions. She has modeled for me how to go about telling an Aboriginal story and how to teach my students about the symbolism in them. (grade one teacher, email communication)

Moll (2014) leans on Vygotsky's socio-cultural theory to say that teachers change themselves in the process of helping to mobilize funds of knowledge for teaching and learning by working with others to help change classrooms for the better. Beyond possessing subject matter and methodological knowledge, "teachers need to develop through their activities a sense of group spirit with which the soul of the school must be infused" (p. 154). Wrestling with theory/practice relationships and tensions, drawing in personal and professional funds of knowledge, and questioning their beliefs about purposes of and practices within education, both transformed and repaired participants' assumptions and beliefs. To live within a school community is to be an integral contributing part of its innermost fundamental reason for being. Collaborative inquiry offers teachers a venue for this learning:

Lastly, from a teacher standpoint, I enjoyed working alongside my advocate and building bridges between my parents in our First Nations community. My advocate became a member of our classroom...My Aboriginal and non-Aboriginal parents really appreciated seeing their cultures highlighted in the students' books. (grade one teacher, written reflection)

\section{The Curriculum for All Project}

Inclusive education literature encourages educators to find strength in and embrace diversity. This value, however, is not reflected in educational settings that still separate students by cognitive ability (Downing, 2008; Willis, 2007). When and if students with developmental disabilities are included, their classroom membership is rarely seen as creating learning opportunities with potential to benefit all students. 
To address this issue, a collaborative, situated professional development initiative was offered in a school district comprising five rural and remote communities. Educators were invited to participate to inquire into their practice related to curricular access for students with a diverse range of abilities. A central design feature of the series involved attending to at least one case study student with a developmental disability, to be included in the curricular plan, as these students are often taught separately or not included in the planning of conceptually rich curricula (Milsom, 2006).

The Curriculum for All inquiry-oriented professional development project offered educators an opportunity to explore this tension in their practice by collaboratively planning instruction, that from the onset, included all of their learners (Rose \& Meyer, 2002; Schnellert, Watson, \& Widdess, 2015; Villa \& Thousand, 2005). The project brought together 10 teacher teams and a district administrator for five sessions between October and June. Together they explored the common question: "How can all students be meaningfully included and contribute in classes, regardless of cognitive ability?"

The facilitator of the project guided participants through various evidence-based planning frameworks including Response to Intervention (RTI), Universal Design for Learning (UDL) (Rose \& Meyer, 2002), Differentiated Instruction (DI) (Tomlinson \& Imbeau, 2010), and Inquiry (Wilhelm, 2007) to (re)consider student diversity, not as a deficit, but rather as a generative foundation for instructional planning, assessment, and curriculum development.

The first session invited educators to (re)examine their philosophies of inclusive education. Here participants had the opportunity to discuss tensions, articulate their beliefs, and set practice goals addressing diversity in their contexts. Building their professional community of inquiry through the exploration of values, goals, and the aims of education was a foundation for these teachers to engage with and shift their practice. The second session required participants to look at evidencebased frameworks that support inclusion including RTI, UDL, DI and inquiry. Knowing their learners was foundational to designing the plan (Childre, Sands, \& Pope, 2009), so teams co-developed a strength-oriented and diversity-positive profile of their class, an essential step in beginning the collaborative planning process. Collaboration partners then designed practices that responded directly to their class's unique profile and characteristics (Schnellert et al., 2015).

In the third session, utilizing the new BC curriculum (BC Ministry of Education, 2014), teams focused on co-planning using UDL principles such as multiple means of engagement, action, and expression (Rose \& Meyer, 2002). UDL principles were used as 
a framework for partners to consider how to increase access, participation, and progress for their diverse learners (Jimenez, Graf, \& Rose, 2007; King-Sears, 2009),

The fourth session zoomed in to look specifically at students with developmental disabilities. Dialogue was facilitated and encouraged around how to make curricular goals meaningful for all students (Browder, 2001; Downing \& McFarland, 2010), as well as, how students with cognitive diversity could contribute to the learning of everyone in the class.

Between the fourth and fifth sessions, collaborative teams implemented and adjusted their plans at the classroom level, an essential component to teacher inquiry (Hopkins \& Levin, 2000), and returned to the fifth session ready to share with the larger inquiry community. Their presentations were organized around three guiding questions: "What did we try? What did we notice? And what did we learn?" This dual focus on practice and learning was intended to support educators to reflect on and explore their emerging knowledge and beliefs while also surfacing teaching practices that welcomed all learners as generative classroom learning community members. Conditions in the large group cross-team learning community meetings were developed to encourage purposeful transformation of classroom practice, but also discourse itself.

Although the large group shared a common overarching question, school collaboration partners were able to choose a lens through which to view their inquiry. The new British Columbia curriculum has organized core-compency areas described in overlapping and interactive themes (BC Ministry of Education, 2014). One team, for example, co-planned an English 8 poetry unit, while another planned a science/ language arts cross-curricular unit in a grade 3/4 class. Other groups planned units focusing on nurturing students' self-regulated learning or social responsibility.

Regardless of lens, one common goal for all teams was to plan according to their specific context. Given that each class had a diverse and unique profile, unit plans were designed with this in mind. One participant mentioned how his team, "planned for the class, rather than for a specific grade" (teacher reflection). This shift to student-centered planning and teaching freed teachers from one-size-fits-all teaching and instructional goals, resulting in more responsive teaching and learning.

Another common goal across the collaborative teams was to increase access to learning for all students. In every classroom, students brought diverse abilities, experiences, cultures, languages, and many other personal and social resources. By designing a unit and lessons with intent to draw upon and accommodate this diversity, 
teachers provided their students with opportunities to connect their experiences and new information through interactions with others in their context (Childre et al., 2009). Additionally, teachers provided multiple access and challenge points within the design of their activities, rather than attempting to retrofit or simplify activities after the fact. A classroom teacher in the project described this as, "the launching point to reach all and adding challenges for the few" (teacher reflection).

A common theme in participants' reflections was the increase in student engagement and participation when lessons welcomed and leveraged diversity as a resource to the classroom rather than a deficit. In her reflection, a resource teacher supporting an English class explained how, "the students LOVED it! They were proud of their work... and wanted to share and listen to each other" (teacher reflection). Another noticed how, "it really increased student engagement with each lesson" (teacher reflection). This is not surprising as research supports an increase in academic engagement when classrooms are designed following UDL principles (Park, Holloway, Arendtsz, Bempechat, \& Li, 2012).

An interesting shift was how teachers noticed students beginning to push themselves further because of the lack of stigma around success and/or failure. Everyone was learning together, but in a variety of ways. A teacher working with a group of secondary students noted how, "[the responsive planning] motivated students to do better than average; they usually were content to do the minimum because their friends were doing that (teacher reflection)." This may have to do with the growing research explaining the power of self-regulated learning in supporting students to control challenge and develop efficacy to understand and complete tasks successfully (Butler \& Schnellert, 2012; Zimmerman, 2008; Zimmerman \& Schunk, 2011). This was evident in teacher reflections. One described how students' perceptions of challenge and ability started to shift, "students who were capable, but lacked self esteem were much quicker to jump into an [activity] when lessons were universally designed. As a result, they passed their own expectations. It made the learning seamless."

The most common theme in the presentations and reflections was how the participants noticed the benefits of working together. Teams were all given time and support to co-plan and implement their units and activities. Every team mentioned how beneficial this was for drawing on one another's expertise and experience in planning to capitalize on the diversity of their specific classes. An additional pattern in participants' responses was how the planning frameworks proved a needed scaffold to teams, allowing them to utilize each other as productive resources. A resource teacher described this saying, "collaboration using [planning] frameworks gave a clear understanding of how to include ALL staff into the planning and implementation 
of lessons [including resource teachers and educational assistants]" (written reflection). Collaboration was a key ingredient in teachers' inquiries and professional development, enabling them to construct, monitor, and adapt their practices in a supportive community.

One particularly popular strategy for creating access in activities and lessons was utilizing diverse and multiple texts in classes (Schnellert et al., 2015). From a UDL perspective, a diverse text set provides multiple engagement and representation points for students; this was a strategy that many teams took advantage of. By designing texts for students with developmental disabilities, teachers extended their understandings of literacy and differentation. As teachers shared their text set as a work in progress, they provoked each other to increase textual modalities and reading levels as part of curriculum design. Teachers referred to this as a significant moment of praxis regarding the creation of entry points for student participation in content area learning with peers. Providing this level of access was a source of learning for many participants, one teacher mentioned that, "making sure that ALL students [were included] in lessons made me realize how I was missing this in the past" (teacher reflection).

Although careful attention was paid to specific supports that individual students required to be successful, when implemented, these supports were utilized by whomever needed them and many teachers noticed this universal benefit. In a K/1 class focusing on self-regulation, for example, a corner of the classroom was designed as a calming space for a particular student who became anxious, but when it came time to implement this strategy, the classroom teacher realized that, "our target student for the 'calming space' was not the first student to independently access it" (field notes). Additionally, in a secondary Social Studies class, a classroom teacher quickly learned, "when I started teaching for ALL, I noticed that some of my other students had an easier job comprehending the material" (written reflection).

All teachers in the Curriculum for All Project experienced shifts in their practice, and they linked these shifts to the power of the inquiry community. This initative highlights the potential of inquiry-oriented professional development models to support teachers to rethink their practice in equity-oriented ways. Embedding extended dialogue and reflection time into such initiatives can support teacher to reexamine and align their beliefs about diversity and inclusive education. At the end of the project one teacher wrote, "having special needs kids in the class helped EVERYONE feel included...I now will always start with ALL," while another noted, "I am learning that inclusion is more than just 'dreaming' of how I think school should be," and a third reflected, "I left every session thinking, I'm going to change the world because now I have a plan!" 
These 20 educators make up one fifth of the entire teaching force in this geograhically spread out, rural school district. Together these educators shifted discourse regarding students with developmental disabilities, framing them as productive members of a their classrooms who can positively impact the learning of their peers and teachers.

\section{Discussion}

Collaborative models of teacher inquiry have the potential to engage teachers in not only shifting their instructional practices and theoretical understandings, but also the structures they work within. These two dialogically focused inquiry groups helped teachers persevere in the exploration and application of new ideas. Educators participating in these inquiry communities were able to envision and enact pluralistic representations and practices of knowing that challenged school- and system-level normative expectations of student achievement. A key component in each of these inquiry groups was that a community of educators came together with a question and/or challenge specific to their students and practice and inquired deeply over time. Clarke and Erickson (2004) note that there is "general agreement that most claims about learning are largely dependent upon the context of the learning environment... [and] the inherent situated and contextually-bound nature of learning" (p. 45). We propose that researchers and learning community facilitators cannot ignore the situated nature of learning and teaching and the myriad factors that impact educators' professional development. In these examples, a focus on situated dialogue attending to social/ discursive factors, combined with the goals teachers set and the actions they took made a difference at multiple levels, informing practice and changing perspectives across the inquiry community. Perhaps most importantly, teachers (re)positioned their work as diversity-positive and drew on their students' funds of knowledge to develop their own pedagogical funds of knowledge.

Cochran-Smith and Lytle (1999) confirm:

teacher research as an agency for classroom and school change. The premise of this approach is that teachers generate local knowledge of teaching, learning and schooling when they make classrooms and schools sites for research, work collaboratively in inquiry communities, and take critical perspectives on the theory and the research of others. This work pays particular attention to the discourse of learning communities, the conjoined efforts of teachers and students as inquirers, and the role of inquiry in the fields of literacy and curriculum. (p. 18) 
In both of these examples, the researcher-facilitator created opportunities for critical reflection. Cranton (1996) suggests that,

critical reflection is the central process in transformative learning. Our natural human interest in emancipation drives us to reflect on the ways we see ourselves, our history, our knowledge, and our social roles [and] if we see that we are constrained or oppressed by any of our perspectives. (p. 75)

Sustained exploration of and reflecton related to equity-oriented theory and practices played a role in challenging educators' views of social dimensions of their classrooms and schools.

In essence, this work troubles the notion of teacher as doer, not thinker; manager, not scholar (Winter, 2000). As we analyzed data, we wondered how and when the teachers in these inquiry communities became comfortable surfacing and honoring multiple perspectives within their classrooms and with one another. Our analyses only begin to reveal how the inquiry communities work as a mediating structure allowing teachers to develop intersubjective ways of knowing and transacting while adding to their funds of pedagogy (Moll, 2014). We can see that change occurred; for example, approaches like the community circle in the Indigeous Early Literacy Project made a difference in helping non-dominant voices have a valued and equal place in both inquiry community meetings and classrooms. But more attention in future studies needs to delve into discursive practices such as the emergent nature of teachers' talk in relation to their practice. We have scratched the surface here. In addition, we need to focus on if and when (and how) teachers tackled systemic barriers (policies, school structures, historical racism) in the same way they worked to make their classrooms more inclusive and reconstituted student success to build from students' strengths and funds of knowledge. Within these two PD examples, inquiry community members shared responsibility for theorizing equity-oriented pedagogy and found agency to create conditions that increased access and success for learners. In particular, educators spoke of how working as school-based inquiry partners and then coming together in the cross-school learning community sustained and propelled their learning-providing opportunities to be inspired and challenged by colleagues. In both of the PD initatives discussed here, educators shared how participating in collaborative pracitioner inquiry as part of cross-school learning communities resulted in new ways of viewing student diversity, not as a problem, but instead as a generative foundation for instructional planning, assessment, and curriculum development. 


\section{Conclusion}

While teachers in the Aboriginal Early Literacy Project and the Curriculum for All Project lived in different communities and taught in different schools in their school districts, they similarly drew from theory, their students, and one another to inform the questioning of their beliefs, assumptions, and practices. While inquiry partners worked together to successfully implement ideas in their schools, they found coming together in larger inquiry communities critical in challenging and transforming their dispositions to diversity as a resource to their teaching and learning. Across participants in both sites, a key attribute of professional development was recognizing and capitalizing on both students' and teachers' funds of knowledge to transform curriculum, pedagogy, and relationships. Providing and faciltiating dialogue within learning community meetings-where teachers deconstructed and reconstructed their professional knowledge and practice-helped them to possibilize as part of their inquiry. Time to deliberate, explore, and co-create with theory and their own students in mind should be a central component in such initiatives. Diversity creates opportunities for learning, clarifying, translating, making the hidden curriculum explicit, challenging it, and seeking to find potential in learners and contexts.

Interestingly, educators in these two initatives spoke of changes in their practice as critical in helping them see and discuss their beliefs, assumptions, and learning. This suggests that professional development initatives benefit from teachers engaging in cycles of action and reflection as they consider social, cultural, and cognitive diversity within their lived experiences. Social justice-oriented professional development benefits teachers when it can support systemic, situated cycles of action and collaborative reflection. The interactional spaces created among community-based inquiry groups can act as mediating structures in which new avenues of discourse and pedagogy are discovered, co-created, assimilated, and collaboratively internalized as functional concepts. In these instances, social justice, equity, context, and student funds of knowledge become the curriculum. In professional development where teachers inquire into the generativity of diversity and plan from and draw on student and teacher funds of knowledge, students and teachers have opportunities to become active agents possibilizing curriculum as situated, co-constructed, and responsive. 


\section{References}

Bakhtin, M. (1981). The dialogic imagination. Austin: University of Texas Press.

Ball, A. (2009). Toward a theory of generative change in culturally and linguistically complex classrooms. American Educational Research Journal, 46(1), 45-72.

Bazerman, C. (2012). Writing with concepts: Communal, internalized, and externalized. Mind, Culture and Activity, 19(3), 259-272.

BC Ministry of Education. (2014). Draft Curriculum. Retrieved from https://curriculum.gov.bc.ca

Bell, N. (2014). Teaching by the medicine wheel. Education Canada, 54(3). Retrieved from http://www.cea-ace.ca/education-canada/ article/teaching-medicine-wheel

Bishop, S. R., Lau, M. A., Shapiro, S. L., Carlson, L., Anderson, N. D., Carmody, J., et al. (2004). Mindfulness: A proposed operational definition. Clinical Psychology, 11, 230-241.

Browder, D. (2001). Curriculum and assessment for students with moderate and severe disabilities. New York: Guilford Press.

Butler, D. L., \& Schnellert, L. (2012). Collaborative inquiry in teacher professional development. Teaching and Teacher Education, 28, 1206-1220.

Butler, D. L., Schnellert, L., \& MacNeil, K. (2015). Collaborative inquiry and distributed agency in educational change: A case study of a multi-level community of inquiry. Journal of Educational Change, 16(1), 1-26

Childre, A., Sands, J.R., \& Pope, S.T. (2009). Backward design. Teaching Exceptional Children, 41(5), 6-14.

Clarke, A., \& Erickson, G. (2004). The nature of teaching and learning in self-study. In Loughran, J.J., Hamilton, M.L., LaBoskey, V.K. and Russell, T.L. (Eds.) The International Handbook of Self-Study of Teaching Practices, 41-67. Dordrecht: Kluwer Academic Publishers.
Cleovoulou, Y., McCollam, H., Ellis, E., Commeford, L. Moore, I., Chern, A., et al. (2013). Using photographic picture books to better understand young children's ideas of belonging: A study of early literacy strategies and social inclusion. Canadian Children, 38(1), 11-20.

Cochran-Smith, M., \& Lytle, S. (1999). The teacher research movement: A decade later. Educational Researcher, 28(7), 15-25.

Cranton, P. (1996). Professional development as transformative learning: New perspectives for teachers of adults. San Francisco: Jossey-Bass.

Dewey, J. (1938a). Experience and education. New York: Collier Books.

Dewey, J. (1938b). What is social study? In Jo Ann Boydston (Ed.), (1988), The later works of John Dewey, 1925-1953 (Vol. 13), 338-341. Carbondale: Southern Illinois University Press.

Dillon, D. R., O'Brien, D. G., \& Heilman, E. E. (2000). Literacy research in the next millennium: From paradigms to pragmatism and practicality. Reading Research Quarterly, 35, 10-26.

Downing, J. E. (2008). Including students with severe and multiple disabilities in typical classrooms: Practical strategies for teachers. Baltimore: Brookes Publishing Co.

Downing, J. E., \& MacFarland, S. (2010). Education and individuals with severe disabilities: Promising practices. In Stone, J.H., Blouin, M. (eds). International Encyclopedia of Rehabilitation.

Fekadu, K. (2014). The paradox in environmental determinism and possibilism: A literature review. Journal of Geography and Regional Planning, 7(7), 132-139.

First Nations Education Steering Committee (FNESC). (2014). Poster First Peoples Principles of Learning. Retrieved from http://www. fnesc.ca/resources/publications/

First Nations Pedagogy Online. (2009). Talking circles. Retrieved from http://firstnations pedagogy.ca/circletalks.html 
Gay, G. (2000). Culturally responsive teaching. New York: Teachers College Press.

Gay, G. (2002). Preparing culturally responsive teaching. Journal of Teacher Education, 53(2) 106-111.

Greeno, J. (2012). Concepts in activities and discourses. Mind, Culture, and Activity, 19(3), 310-313.

Hedges, H. (2015). Sophia's funds of knowledge: Theoretical and pedagogical insights, Possibilities and dilemmas. International Journal of Early Years Education, 23(1), 83-96.

Hopkins, D., \& Levin, B. (2000). Government policy and school improvement. School Leadership and Management, 20(1), 15-30.

Jimenez, T. C., Graf, V. L., \& Rose, E. (2007). Gaining access to general education: The promise of universal design for learning. Issues in Teacher Education, 16(2), 41-54.

King-Sears, M. (2009). Universal design for learning: Technology and pedagogy. Learning Disabilities Quarterly, 32, 199-201.

Ladson-Billings, G. (1995). Toward a theory of culturally relevant pedagogy. American Educational Research Journal, 32(3), 465-491.

Milsom, A. (2006). Creating positive school experiences for students with disabilities. Professional School Counseling Journal, 10(1), 66-72.

Moll, L. C. (2014). L.S. Vygotsky and education. New York: Routledge.

Park, S., Holloway, S. D., Arendtsz, A., Bempechat, J., \& Li, J. (2012). What makes students engaged in learning? A time-use study of within- and between-individual predictors of emotional engagement in low-performing high schools. Journal of Youth and Adolescence, 41, 390-401.

Rose, D. H., \& Meyer, A. (2002). Teaching every student in the digital age: Universal design for learning. Alexandria, VA: Association for Supervision and Curriculum Development (ASCD).

Rowsell, J. (2006). Family literacy experiences: Creating reading and writing opportunities that support classroom learning. Markham, Ontario: Pembroke.
Schnellert, L., \& Butler, D.L. (2014, June). Collaborative inquiry: Empowering teachers in their professional development. Education Canada, 54(3), 18-22.

Schnellert, L., Richardson, P., \& Cherkowski, S. (2014). Teacher educator professional development as reflexive inquiry. LEARNing Landscapes, 8(1), 233-250.

Schnellert, L., Watson, L., \& Widdess, N. (2015). It's all about thinking: Creating pathways for all learners in the middle years. Winnipeg, MB: Portage \& Main Press.

Tomlinson, C. A., \& Imbeau, M. B. (2010). Leading and managing a differentiated classroom. Alexandria, VA: Association for Supervision and Curriculum Development (ASCD).

Van Horn, L. (2006). Re-imagining professional development. Voices From the Middle, 13(4), 58-63.

Villa, R., \& Thousand, J. (2005). Creating an inclusive school. Alexandria, VA: Association for Supervision and Curriculum Development (ASCD).

Vygotsky, L. S. (1978). Interaction between learning and development (M. LopezMorillas, Trans.). In M. Cole, V. John-Steiner, S. Scribner, \& E. Souberman (Eds.), Mind in society: The development of higher psychological processes (pp. 79-91). Cambridge, MA: Harvard University Press.

Vygotsky, L. S. (1987). Thinking and speech ( $N$. Minick, Trans.). In R. W. Rieber \& A. S. Carton (Eds.), The collected works of L. S. Vygotsky: Vol. 1. Problems of general psychology (pp. 39-285). New York: Plenum Press. (Original work published 1934)

Wells, G. (2007). Who we become depends on the company we keep and on what we do and say together. International Journal of Educational Research, 46, 100-103.

Wertsch, J. V. (2010). Vygotsky and recent developments. In E. Baker, B. McGaw, \& P. Peterson (Eds.), International encyclopedia of education (3rd ed.) (pp. 231-236). Oxford: Elsevier.

Wilhelm, J.D. (2007). Engaging readers and writers with inquiry. New York: Scholastic. 
Willis, J. (2007). Brain-friendly strategies for the inclusion classroom. Alexandria, VA: Association for Supervision and Curriculum Development (ASCD).

Winter, C. (2000). The state steers by remote control: Standardising teacher education. International Studies in Sociology of Education, 10(2), 153-175.

Zimmerman, B. J. (2008). Investigating self-regulation and motivation: Historical background, methodological developments, and future prospects. American Educational Research Journal, 45(1), 166-183.
Zimmerman, B. J., \& Schunk, D. H. (2011). Selfregulated learning and performance. In B. J. Zimmerman and D. H. Schunk (Eds.), Handbook of self-regulation of learning and performance (pp. 1-12). New York: Routledge.

Zipin, L. (2009). Dark funds of knowledge, deep funds of pedagogy: Exploring boundaries between lifeworlds and schools. Discourse: Studies in the Cultural Politics of Education, 30(3), 317-331.

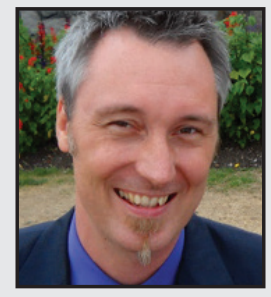

Leyton Schnellert researches teacher learning, practice, and collaboration. He attends to how teachers and teaching and learners and learning can mindfully embrace student diversity, inclusive education, self- and co-regulation, and literacy instruction. Leyton is the Pedagogy and Participation research cluster lead in UBCO's Institute for Community Engaged Research. His community-based collaborative work contributes a counterargument to top-down approaches that operate from deficit models, instead drawing from communities' funds of knowledge to build participatory, collaborative, and culturally responsive practices. His scholarship takes up pedagogy and related research working from epistemological orientations to living and learning that are relational and community-honouring. 


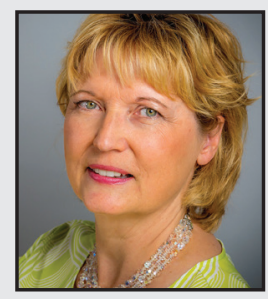

Donna Kozak has been a teacher for 30 years, beginning her career in the primary grades. She has also been a literacy teacher for students in middle school. Over the last few years, she has worked with teachers of young children in early language and literacy development and coordinated school district projects focusing on diversity, inclusion, and mentorship for new teachers. Donna is currently a PhD student studying the interplay between lifeworlds, school literacies, and the potential of parents and teachers as learning partners. She is an adjunct instructor teaching literacy courses in UBCO's elementary teacher education and post-baccalaureate programs.

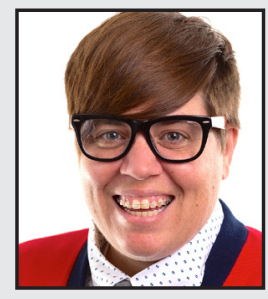

Shelley Moore is based in Vancouver, British Columbia and her research spans both curriculum and special education. She collaborates with various school districts to explore and implement inclusive programming for students with developmental disabilities throughout British Columbia. She has presented her work at various conferences throughout North America including CSSE, CEC, IRA, and NCTE. She completed an undergraduate degree in Special Education at the University of Alberta, her Masters at Simon Fraser University, and is currently a PhD student at the University of British Columbia. 